\title{
Activated Carbon as Adsorbent In Advance Treatement of Wastewater
}

\author{
Vikash R Agrawal $^{1}$, Vikrant S Vairagade ${ }^{2}$, Amol P Kedar $^{3}$ \\ 1, 2, 3 (Department of Civil, Priyadarshini College of Engineering, Nagpur, Maharashtra, India)
}

\begin{abstract}
A treatability study was carried out on wastewater collected from Bhandewadi Wastewater treatment plant, Nagpur, Maharashtra. The aim of the research work was to check out whether the activated carbon (AC) gives maximum removal of BOD, COD, $\mathrm{pH}$, Turbidity from wastewater sample. The present research work was undertaken to find out percentage of activated carbon is more efficient for removing the characteristics of wastewater like BOD, COD for safe disposal in water streams and land. The raw wastewater is put under contact of activated carbon and checked the efficiency of the activated carbon for reducing down the harmful parameters. The wastewater is given an exposure to activated carbon at 2\%, 4\% and $6 \%$ for 7 and 14 days.
\end{abstract}

Keywords: $B O D, C O D, p H$, Turbidity, Activated carbon (AC)

\section{Introduction}

Wastewater: Wastewater is any water that has been adversely affected in quality by anthropogenic influence. Wastewater can originate from a combination of domestic, industrial, commercial or agriculture activities, surface runoff or storm water and from sewer inflow or infiltration. Municipal wastewater is usually conveyed in a sanitary sewer, and treated at a wastewater treatment plant. Treated wastewater is discharged into receiving water via an effluent pipe. Wastewaters generated in areas without access to centralized sewer systems rely on on-site wastewater systems. These typically comprise a septic tank, drain field, and optionally an on-site treatment unit. The management of wastewater belongs to the overarching term sanitation, just like the management of human excreta, solid waste and storm water. Wastewater is $99.9 \%$ water. The other $0.1 \%$ is what a cause for concern is. That $0.1 \%$ includes, Nutrients: Phosphorous and Nitrogen, Fats, oils, grease: cooking oils, body lotions, Pathogens: disease-causing bacteria and viruses, BOD-biochemical oxygen demand. BOD is a measure of oxygen needed by aerobic bacteria to break down organic matter. A higher BOD means there is more organic matter that needs to be broken down other solids.

Activated Carbon: Activated Carbons are the most powerful adsorbents known. It is basically a solid material consisting mainly of pure carbon. A characteristic feature is its porous structure and the resulting immense surface area which may be as large as $1500 \mathrm{~m} 2 / \mathrm{gm}$. Due to its exceptional adsorption qualities, activated carbon is widely used in process destined to purify, discolor, recuperate and remove odors at low cost and superior efficiency. Activated carbons work on the principle of adsorption. Adsorption is an interfacial process involving the collection of gaseous or solute components on the surface of adsorbent solids. This phenomenon is associated with physical attractive forces that bind gaseous and solute molecules commonly known as Van-derWaals forces. Adsorption is thus a physical process, i.e. the substances adsorbed on the solid do not undergo any chemical reaction with the latter. The adsorbing solid is referred to as adsorbent and the substance to be adsorbed from the liquid or the gas phase as the solute. The adsorption power and rate is determined by the kind of activated carbon, the particle size, the pore size and its distribution.

Adsorption: The process by which molecules of the substance, such as a gas or a liquid, collect on the surface of another, such as a solid. The molecules are attracted to the surface but do not attracted to the solid's minute spaces, as absorption. Some drinking water filters consist of carbon cartridges that adsorb contaminants.

Biochemical oxygen demand (BOD): Biochemical oxygen demand (BOD, also called biological oxygen demand) is the amount of dissolved oxygen needed by aerobic biological organisms to break down organic material present in a given water sample at certain temperature over a specific time period. The BOD value is most commonly expressed in milligrams of oxygen consumed per liter of sample during 5 days of incubation at $20{ }^{\circ} \mathrm{C}$ and is often used as a surrogate of the degree of organic pollution of water. This is a measure of the amount of molecular oxygen in milligrams required to convert organic molecules contained in 1.0 liter of a water sample to $\mathrm{CO}_{2}$. Microorganisms such as bacteria are responsible for decomposing organic waste. When organic matter such as dead plants, leaves, grass clippings, manure, sewage, or even food waste is present in a water supply, the bacteria will begin the process of breaking down this waste. When this happens, much of the available dissolved oxygen is consumed by aerobic bacteria, robbing other aquatic organisms of the oxygen they need to live. BOD level is a common metric for water pollution. The BOD level is determined by comparing the dissolved oxygen levels of a water sample before and after 5 days of incubation in the dark (see the next section 
for this). The difference between the two DO levels represents the amount of oxygen required for the decomposition of any organic material in the sample and is a good approximation of the BOD level.

Chemical oxygen demand (COD): This is another measure of the oxidizable organic compounds in water. In this method, organic materials are oxidized to $\mathrm{CO}_{2}$ with dichromate in acidic solution. Dichromate doesn't oxidize ammonia and this can give a reading that underestimates the biological oxygen demand. Ammonia decomposition to nitrate uses molecular oxygen. Dichromate can oxidize other inorganic components of water, and this produces a BOD estimate that is too high. In a COD measurement, a known, excess amount of potassium dichromate and sulfuric acid are added to the sample. COD is a measure of the oxygen equivalent of that portion of organic matter in a sample that is susceptible to oxidation by a strong chemical oxidant. This is an important and quickly measured parameter for stream and industrial waste studies and control of waste treatment plants.Most type of organic matter are completely oxidized by a boiling mixture of chromic and sulphuric acid to produce $\mathrm{CO}_{2}$ and $\mathrm{H}_{2} \mathrm{O}$. A measure quantity of the sample is refluxed with a knowing unreacted is titrated with ferrous ammonia solution. The $\mathrm{K}_{2} \mathrm{Cr}_{2} \mathrm{O}_{7}$ consume is proportional to the amount of oxidizable organic matter measured as oxygen equivalent.

pH:The given sample $\mathrm{pH}$ is measured by a $\mathrm{pH}$ meter using a glass electrode which generates a potential varying linearly with the $\mathrm{pH}$ of the solution in which it is immersed. $\mathrm{pH}$ is a measure of acid base equilibrium and achieve by various dissolved compound and in most natural water is control by carbon dioxide $\left(\mathrm{CO}_{2}\right)$, carbonate $\left(\mathrm{CO}_{3}\right)$, bicarbonate $(\mathrm{HCO} 3)$,equilibrium system. $\mathrm{pH}$ of solution refer to its hydrogen iron activity. It is also defined as the negative logarithm of hydrogen iron concentrated.

$$
\mathrm{pH}=-\log [\mathrm{H}+]
$$

Turbidity: When light is passed through a sample having suspended particle, some of the light is scattered by the particles. The scattering of the light is generally proportional to the turbidity. The turbidity of the sample is thus measured from the amount of the light scattered by the sample taken a reference with standard turbidity suspension. A source is a combination with a obtical component produce a light beam focus on the turbid solution. The light is scattered by the suspended particles in the solution. The scattered light is sensed by a photocell kept at $90^{\circ}$ in the light path the amount of scattered light sensed by photo sell is a direct measure of turbidity. Turbidity is measure of degree to which the water loses its transparency due to the presence of suspended particulate. Turbidity is considered as a good measure of quality of water. Turbidity is measured in NTU (Nephelometric turbidity unit). The instrument used for measuring it is called as Nephelometer or Turbidmeter, Which measured the intensity of light scattered at $90^{\circ}$ as beam of light passed through a water sample. The unit use in ancient time is JTU (Jackson turbidity unit) measured in Jackson candle turbidmeter. Technically, turbidity is an optical property of the water base on the amount of light reflected by suspended particles. When particles are suspended in water and a light is shined through the sample, not all the light will pass straight through the sample.

\section{Permissible standard for disposal of wastewater}

Table 1.1: Permissibe results and Effluent result of Bhandewadi WWTP

\begin{tabular}{|l|c|c|}
\hline Parameters & $\begin{array}{l}\text { Ranges as per CPHEEO, WHO and } \\
\text { CPCB }\end{array}$ & $\begin{array}{l}\text { Effluent results at Bhandewadi } \\
\text { WWTP }\end{array}$ \\
\hline $\mathrm{pH}$ & 5.5 to 9.0 & 7.58 \\
\hline BOD $(\mathrm{mg} / \mathrm{l})$ & $<30$ & 16 \\
\hline $\mathrm{COD}(\mathrm{mg} / \mathrm{l})$ & $<250$ & 58 \\
\hline Turbidity (NTU) & 5 & - \\
\hline
\end{tabular}

\section{Methodology And Results}

\section{pH of Wastewater}

The determination can be carried our either by the electrometric method or indicator method. I case of dispute the electrometric method shall be considered as accurate method. Electrometric method: The $\mathrm{pH}$ is determined by measurement of electromotive force of a cell comprising an indicator electrode (an electrode responsive to hydrogen ions such as glass electrode) contact between the test solution and the reference is usually achieved by a means of a liquid function which forms a part of a reference electrode. The electromotive force of the cell is measured with $\mathrm{pH}$ meter. The electrode is firstly dipped into a standard solution od $\mathrm{pH} 7.0$ to calibrate the $\mathrm{pH}$ meter. After proper calibration the electrode is dipped into the test sample and the value of $\mathrm{pH}$ is directly noted down. The $\mathrm{pH}$ of initial wastewater sample is found out to be 7.31 .

Table 2.1: $\mathrm{pH}$ results for 7 days and 14 days

\begin{tabular}{|c|c|c|}
\hline Percentage of Activated carbon(AC) & pH after 7 days & pH after 14 days \\
\hline $2 \%$ & 5.68 & 7.23 \\
\hline $4 \%$ & 6.21 & 7.32 \\
\hline $6 \%$ & 7.10 & 6.43 \\
\hline
\end{tabular}




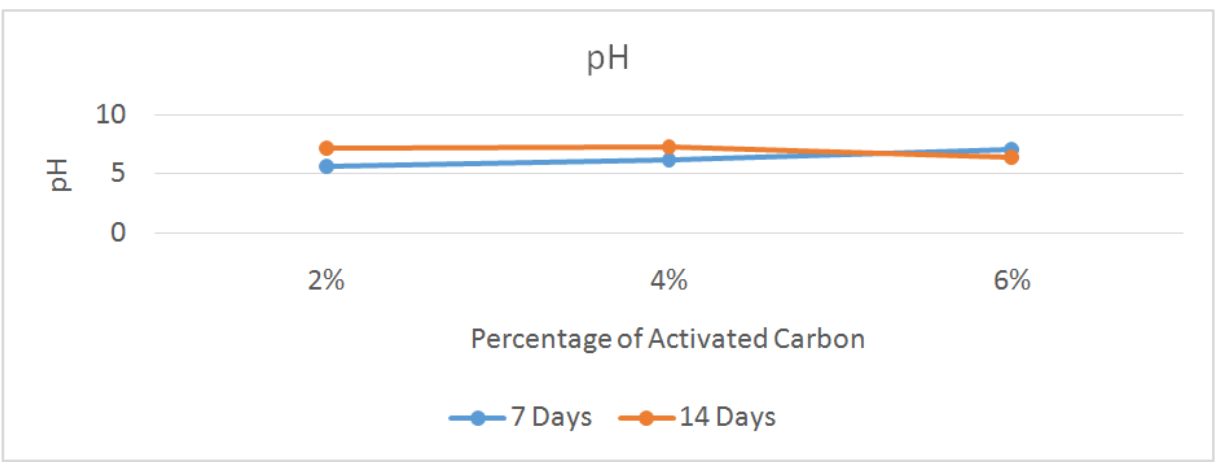

Fig 2.1: $\mathrm{pH}$ and Percentages of $\mathrm{AC}$

\section{Turbidity}

Insert the plug into socket and switch on the instrument and give 15 to 20 minutes warm-up time. Insert the cell with 400 NTU solution into cell holder and cover the cell with light shield. Now calibrate the machine using fine and coarse knobs to 400 NTU. Now take another cell with the test sample and take the reading using same procedure. The turbidity of different wastewater sample is given below:

The turbidity of initial raw wastewater sample is found out to be 57 NTU.

Table 2.2: $\mathrm{pH}$ results for 7 days and 14 days

\begin{tabular}{|c|c|c|}
\hline Percentage of Activated carbon(AC) & Turbidity in NTU after 7 days & Turbidity in NTU after 14 days \\
\hline $2 \%$ & 4 & 5 \\
\hline $4 \%$ & 2 & 3 \\
\hline $6 \%$ & 3 & 4 \\
\hline
\end{tabular}

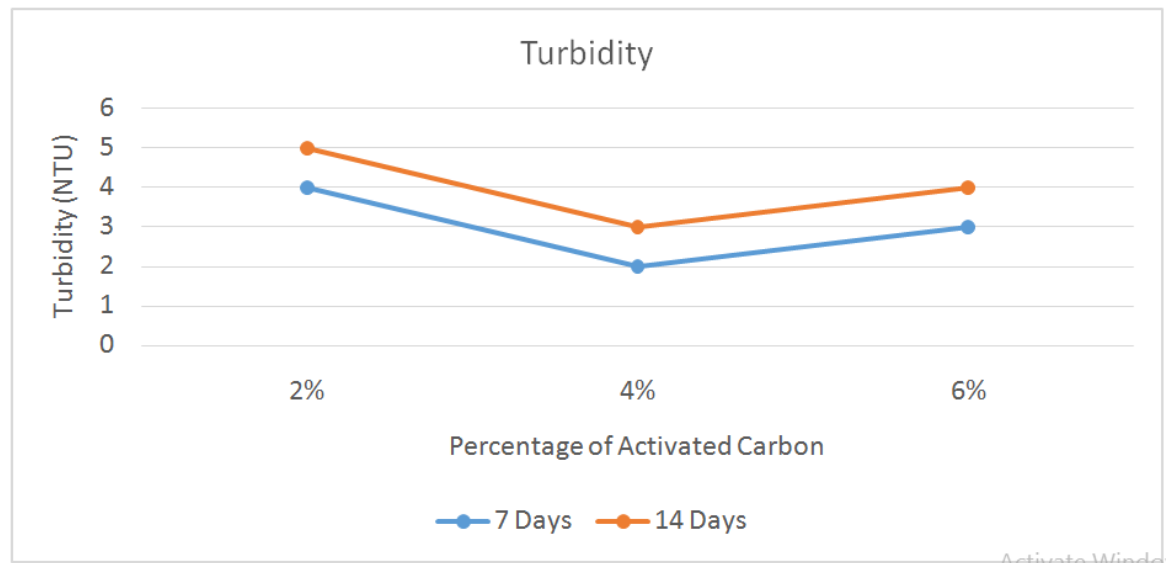

Fig 2.2: Turbidity and Percentages of AC

\section{Biochemical Oxygen Demand}

For dilution of water add $1 \mathrm{ml}$ each of $\mathrm{CaCl}_{2}, \mathrm{MgSO}_{4}, \mathrm{FeCl}_{3}$ phosphate buffer solutions per liter of the above aerator distilled water and mix thoroughly. This standard distil water should be prepared just before taking all the tests. It is preferable to make a series of dilutions for a sample such that at least three of the dilutions should deplete $20 \%$ to $90 \%$ of the initial dissolved oxygen (DO). The COD value may be treated as guideline for dilution. Firstly the initial $\mathrm{DO}$ is found out as $\mathrm{DO}_{0}$ and then kept for 5 days at $20^{\circ} \mathrm{C}$. After 5 days again the final $\mathrm{DO}$ is calculated as $\mathrm{DO}_{5}$. The $\mathrm{BOD}$ of the given water sample may be calculated as:

$$
\text { BOD in } \mathrm{mg} / \mathrm{l}=\frac{(\mathrm{DO0}-\mathrm{DO} 5) \times \text { Volume of BOD bottle }}{\text { Percentage of dilution of Wastewater }}
$$

The results of the BOD are as follows:

The initial value of BOD at Day 1 is found out to be $307.5 \mathrm{mg} / \mathrm{l}$.

Table 2.3: $\mathrm{pH}$ results for 7 days and 14 days

\begin{tabular}{|c|c|c|}
\hline Percentage of Activated carbon(AC) & BOD in mg/l after 7 days & BOD in mg/l after 14 days \\
\hline $2 \%$ & 60 & 31.3 \\
\hline $4 \%$ & 49.5 & 16.95 \\
\hline $6 \%$ & 187.5 & 115.95 \\
\hline
\end{tabular}




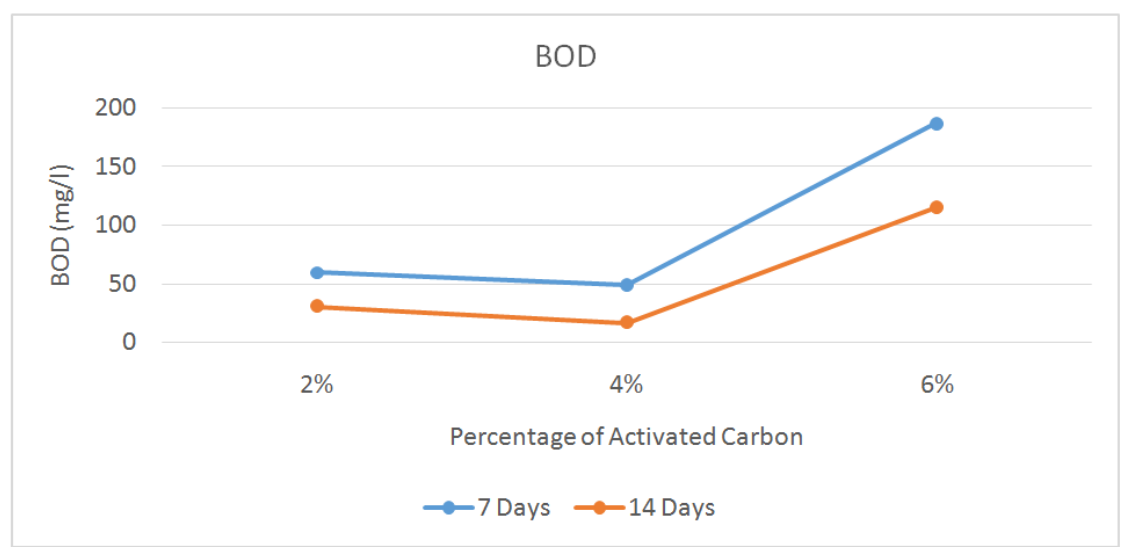

Fig 2.3: $\mathrm{BOD}$ and Percentages of AC

CHEMICAL OXYGEN DEMAND: Place $0.4 \mathrm{~g}$ of $\mathrm{HgSO}_{4}$ in a reflex flask and add $20 \mathrm{ml}$ of the sample or an aliquot of the sample diluted to $20 \mathrm{ml}$ with distilled water. mix well and add $10 \mathrm{ml}$ of $0.25 \mathrm{~N} \mathrm{k}_{2} \mathrm{Cr}_{2} \mathrm{O}_{7}$ solution. Drop some pumice stone and slowly add $30 \mathrm{ml} \mathrm{H}_{2} \mathrm{SO}_{4^{-}} \mathrm{Ag}_{2} \mathrm{SO}_{4}$ reagent while continuously swirling the flask. If the colour changes to green add more $\mathrm{k}_{2} \mathrm{Cr}_{2} \mathrm{O}_{7}$ and $\mathrm{H}_{2} \mathrm{SO}_{4}-\mathrm{Ag}_{2} \mathrm{SO}_{4}$ reagent or alternatively discard the solution and take a fresh sample with lesser aliquot. Mix the contents of the flask thoroughly. connect the flask to the condenser and slowly heat flask. reflex for atleast 2 hours cool and wash down the condenser with distilled water such that the washings fall into the flask . dilute to above $150 \mathrm{ml}$, cool and titrate the unreacted $\mathrm{k}_{2} \mathrm{Cr}_{2} \mathrm{O}_{7}$ with the N/10 ferrous ammonium sulphate solution using ferroin as indicator . the colour change at the end point is from blue green to wine red. the COD of given water sample is calculated as follows :

COD in $\mathrm{mg} / \mathrm{l}=\frac{(V 1-V 2) \times N \times 800}{x}$

Where, $\mathrm{V}_{1}=$ Volume of ferrous ammonium sulphate run down in the blank experiment.

$\mathrm{V}_{2}=$ Volume of ferrous ammonium sulphate run down in the test experiment

$\mathrm{N}=$ Normality of ferrous ammonium sulphate solution $=0.1$

$\mathrm{x}=$ Volume of test sample taken

The result of COD is as follows:

The initial value of COD for wastewater is found out to be $276 \mathrm{mg} / \mathrm{l}$.

Table 2.1: $\mathrm{pH}$ results for 7 days and 14 days

\begin{tabular}{|c|c|c|}
\hline Percentage of Activated carbon(AC) & COD in mg/l after 7 days & COD in mg/l after 14 days \\
\hline $2 \%$ & 104 & 92 \\
\hline $4 \%$ & 88 & 64 \\
\hline $6 \%$ & 76 & 56 \\
\hline
\end{tabular}

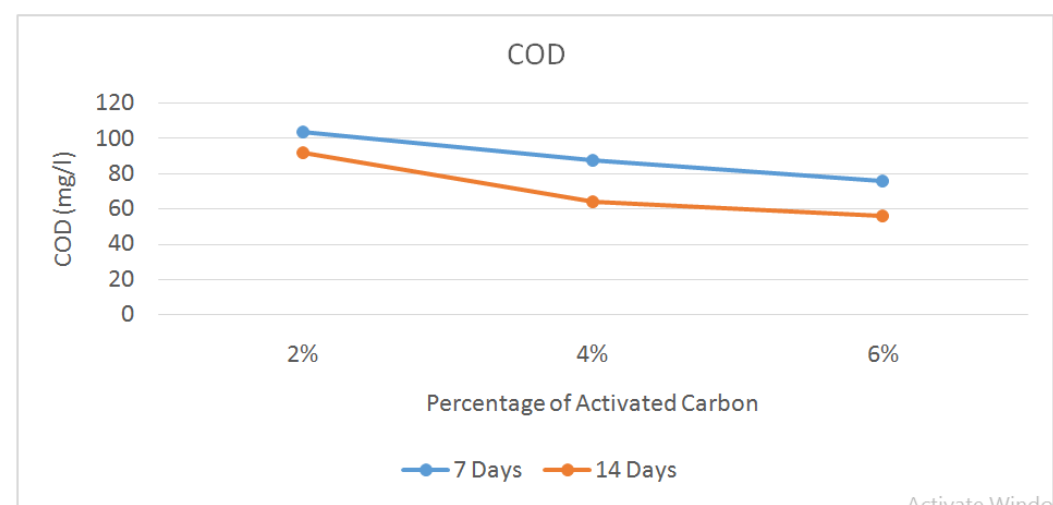

Fig 2.4: $\mathrm{COD}$ and Percentages of $\mathrm{AC}$

\section{Conclusion}

$\mathrm{pH}$, Turbidity, BOD and COD of the treated wastewater is under the permissible ranges of standards mentioned above.We can conclude that the $4 \%$ of AC gives the efficient result for treatment after 14 days. We can suggest that activated carbon can be used as modern technique for treatment of wastewater.The BOD initially decreases after $2 \%$ and $4 \%$ Activated carbon application and then abruptly increases for $6 \%$. So, 5\% AC tests is to be carried out for given days to find out whether it is giving efficient result. 


\section{References}

[1] Saad A. Al-Jlil,COD and BOD reduction of waste water using activated sludge, Sand filters and activated carbon in Saudi Arabia., Biotechnology 8 (4); 473-477, 2009, ISSN 1682-296X

[2] AmudaO. S and Ibrahim A. O, Industrial wastewater treatment using natural material as adsorbent., African journal of biotechnology, Vol 5 (16), PP 1483-1487, 17 August 2006.

[3] Ademiluyi, F. T. ; Amadi, S. A. ; Amakama, NisinghaJacob, Adsorption and treatment of organic contaminants using activated carbon from waste nigerian bamboo, Jasemissn 1119-8362, J. Appl. Sci. Environ. Manage. September 2009 , Vol 13 (3), $39-47$.

[4] J.W Snyder Jr., Craig.N.Mains, Robert.e.Anderson\&Gary.K.Bissonnett .Effect of point of use, activated carbon filters on the bacteriological quality of rural ground water supplies,Applied and environmental microbiology, American society of microbiology, Dec 1995, P. 4291-4295, Vol 61, No.12.

[5] Ann lemley, Linda Wagenet and BarberaKneen,Activated carbon treatment of drinking water, Cornell University 329 FS $338 / 100$. REV.12/955 MSV MS 50178

[6] GazalaSayed, Treatability study of wastewater using activated carbon, sand filters and dual media filters, national conference of biodiversity

[7] J.D.Walk and C.G.Grieves,Powered carbon improves activated sludge treatment (1977), Environmental management , pg.no 125

[8] Mohamed NageebRashed,Adsorption technique for the removal of organic pollutants from water and wastewater, pg. no. 167

[9] Victoria O. Idod and Emmanuel E. Egbon,Treatment of saloon wastewater using activated carbon

[10] Richard W. Farmer, Improved granular activated carbon for the stabilization of wastewater pH (1996)”, pg. no. 456.

Vikash R Agrawal. "Activated Carbon as Adsorbent In Advance Treatement of Wastewater ." IOSR Journal of Mechanical and Civil Engineering (IOSR-JMCE) 14.4 (2017): 36-40. 